\title{
Single-port Laparoscopic Surgery: A Mini Review
}

\author{
Reno Rudiman ${ }^{1}$, Andika A Winata ${ }^{2}$
}

\begin{abstract}
Introduction: Operative laparoscopy has advanced progressively since 1987 after laparoscopic cholecystectomy by means of four trocars. One of the main advantages of laparoscopic surgery over traditional open surgery is that it often requires a shorter hospital stay than traditional open surgery. Compared to conventional laparoscopic surgery, single incision laparoscopic surgery (SILS) has more benefits. In this article, we review laparoscopic surgery with single incision.

Materials and methods: Literature review was performed on newly minimal invasive approach for laparoscopic surgery.

Results: Single incision laparoscopic surgery has advantages in minimizing the invasiveness of surgical incision, reducing the number of incisions and the associated possible wound morbidities. This includes the reduced risks of wound infection, pain, bleeding, organ injury, and port site hernia. Even though SILS is recognized to be a more complicated procedure and costly, patients are experiencing less pain and almost scarless wound.

Conclusion: Single incision laparoscopic surgery is an exciting new approach in the field of laparoscopic surgery.

Keywords: Laparoscopic surgery, SILS, Single port.

World Journal of Laparoscopic Surgery (2018): 10.5005/jp-journals-10033-1356
\end{abstract}

\section{INTRODUCTION}

Surgery to treat various diseases has been recorded back to the middle ages. For two centuries, large incisions were necessary to perform abdominal surgical procedures. Although effective, several known morbidities were related to this method, including postoperative pain, wound infection, incisional hernia, and prolonged hospitalization. ${ }^{1}$ The present surgical site infection rate is $15-25 \%$, depending on the level of contamination. ${ }^{2}$

Laparoscopic surgery was introduced in 1983 by Lukichev and 1985 by Muhe who performed laparoscopic cholecystectomy. Their cumbersome techniques did not receive the attention they probably deserved. Interest started to grow after Mouret in 1987 reported the first acknowledged laparoscopic cholecystectomy by means of four trocars. ${ }^{3}$ Since then, operative laparoscopy has advanced progressively. Several operative procedures have been performed by this new approach. Due to its minimal invasiveness to the abdominal wall, laparoscopic surgery is also called minimally invasive surgery. Laparoscopic procedures can be performed using small incisions of around $0.5-1.5 \mathrm{~cm}$ that can be made far away from the surgical site. Small surgical instruments can then be inserted through the incision and passed through to the operational site. The whole procedure is performed using a laparoscope, which is a camera instrument that can relay live video images from inside the body to a TV monitor. ${ }^{4}$

\section{Literature Review}

One of the main advantages of laparoscopic surgery over traditional open surgery is that it often requires a shorter hospital stay than traditional open surgery. Procedures such as appendectomy or cholecystectomy require the patient to stay at the hospital for only one night after surgery. This is because patients experience less pain and bleeding after surgery. ${ }^{5}$

Another important advantage of laparoscopic surgery is that as the incision wound is much smaller than open surgery, post-surgical scarring is significantly reduced. Cosmetically, it is more desirable
1,2Department of Digestive Surgery, Padjadjaran University, Bandung, West Java, Indonesia

Corresponding Author: Reno Rudiman, Department of Digestive Surgery, Padjadjaran University, Bandung, West Java, Indonesia, Phone: +62 81310008995, e-mail: andhika.august@gmail.com

How to cite this article: Rudiman R, Winata AA.Single-port Laparoscopic Surgery: A Mini Review. World J Lap Surg 2018;11(3):149-150.

Source of support: Nil

Conflict of interest: None

to most patients. Risks of keloid formation is therefore significantly reduced as well. ${ }^{6}$

In conventional laparoscopic surgery, 3-4 small incisions are made. In a more complex procedure such as large bowel resection or bariatric (obesity) surgery, up to six incisions can be made, allowing more instruments to be used to assist organ resection. ${ }^{4,7-9}$ Obviously, the more the wounds made, the more pain it will eventually cause to the patients. On the contrary, less wound signifies less pain. This brings about the concept of Single incision laparoscopic surgery (SILS). ${ }^{10,11}$

Single incision laparoscopic surgery has many other names, including laparo-endoscopic single-site surgery, single-port access surgery, trans-umbilical endoscopic surgery, and one-port umbilical surgery. There is no standardized name so far. ${ }^{12}$

With this technique, the surgeon operates exclusively through a single entry point, typically at the patient's umbilicus. Unlike a traditional multiport laparoscopic approach, SILS leaves only a single small scar. During the years following the introduction of SILS in 1997, enthusiasm was limited because of lack of technical support and poor equipment. In 2005, Hirano et al. ${ }^{13}$ reintroduced the technique with some advancements compared to previous techniques. Since then, the technology has progressed steadily. Among advancements created were articulating instruments, laparoscope adjustments, several trocars adjacent to each other through a single incision.

(c) The Author(s). 2018Open Access This article is distributed under the terms of the Creative Commons Attribution 4.0 International License (https://creativecommons. org/licenses/by-nc/4.0/), which permits unrestricted use, distribution, and non-commercial reproduction in any medium, provided you give appropriate credit to the original author(s) and the source, provide a link to the Creative Commons license, and indicate if changes were made. The Creative Commons Public Domain Dedication waiver (http://creativecommons.org/publicdomain/zero/1.0/) applies to the data made available in this article, unless otherwise stated. 
Single incision laparoscopic surgery is gaining popularity due to its advantages in minimizing the invasiveness of surgical incisions. With the reduced number of incisions, the associated possible wound morbidities will also be reduced. This includes the reduced risks of wound infection, pain, bleeding, organ injury, and port site hernia. ${ }^{12}$ In addition, one important feature of SILS is that since the wound is at umbilicus, it leaves a single small scar that is well-hidden, it is almost unseen when the wound is healed, thereby it is almost "scarless".

In the beginning of SILS introduction, procedures were limited to simple operations such as cholecystectomy and appendectomy. With the increased experience of surgeons and better equipment features, SILS now can be practiced on more complex procedures such as colon resections and bariatric surgery.

In general, SILS techniques take about the same amount of time as traditional laparoscopic surgeries. However, SILS is recognized as a more complicated procedure because it involves manipulating three articulating instruments through one access port. From a financial point of view, the use of a single-port device and the increased skills needed to perform, SILS is slightly more costly compared to the conventional multiport laparoscopic surgery. However, along with many benefits, SILS often offers overall financial advantages to hospitals, patient's healthcare insurance options, and employers, too. Typically, the patient's hospital stay is shorter as well as less medical assistance is needed compared to traditional laparoscopic surgeries.

Although SILS offers desirable benefits for any wide variety of patients undergoing abdominal surgery, not everyone is an applicant for the procedure. Obesity, severe adhesions, or scarring from previous surgeries are a few of the factors that would prohibit patients from undergoing this surgery. Nonetheless, new technologies are evolving continuously. The invention of new surgical tools will hopefully overcome the current obstacles in SILS in the future.

\section{ConcLusion}

Single incision laparoscopic surgery is an exciting new approach in the field of laparoscopic surgery. Patients will recover uneventfully, with minimal postoperative pain, and with minimal scar almost unseen. The increased cost of the surgery is traded off by a shorter hospital stay and faster recovery.

\section{References}

1. Dindo D, Demartines $\mathrm{N}$, et al. Classification of surgical complications: a new proposal with evaluation in a cohort of 6336 patients and results of a survey. Ann Surg 2004;204(2):205-213. DOI: 10.1097/01. sla.0000133083.54934.ae.

2. Azoury S, Farrow N, et al. Postoperative abdominal wound infection-epidemiology, risk factors, identification, and management. Chronic Wound Care Manag Res 2015;2:137-148. DOI: 10.2147/ CWCMR.S62514.

3. Vecchio R, MacFayden BV, et al. History of laparoscopic surgery. Panminerva Med 2000;42(1):67-90.

4. Haribhakti SP, Mistry JH. Techniques of laparoscopic cholecystectomy: Nomenclature and selection. J Minim Access Surg 2015;1(2):113-118. DOI: 10.4103/0972-9941.140220.

5. Bruhat MA, Chapron C, et al. The benefit and risks of laparoscopic surgery (in French). Rev Fr Gynecol Obstet 1993;88(2):84-88.

6. Agha R, Muir G. Does laparoscopic surgery spell the end of the open surgeon? J R Soc Med 2003;96(11):544-546. DOI: 10.1177/014107680309601107.

7. McCormack K, Scott NW, et al. Laparoscopic techniques vs open techniques for inguinal hernia repair. Cochrane Database Syst Rev 2003(1):CD001785. DOI: 10.1002/14651858.CD001785.

8. Reichenbach DJ, Tackett AD, et al. Laparoscopic colon resection early in the learning curve. What is the appropriate setting? Ann Surg 2006;243(6):730-737. DOI: 10.1097/01.sla.0000220039. 26524.fa.

9. Khwaja HA, Bonanomi G. Bariatric surgery: techniques, outcomes and complications. Curr Anaest Crit Care 2010;21(1):31-38. DOI: 10.1016/ j.cacc.2009.10.005

10. Budzynski A, Matlok M, et al. SILS (single incision laparoscopic surgery) - a new surgical approach to peritoneal cavity. Adv Med Sci 2011;56(1):18-24. DOI: 10.2478/v10039-011-0007-1.

11. Froghi $\mathrm{F}$, Sodergren $\mathrm{MH}$, et al. Single-incision Laparoscopic Surgery (SILS) in general surgery: a review of current practice. Surg Laparosc Endosc Percutan Tech 2010;20(4):191-204. DOI: 10.1097/ SLE.0b013e3181ed86c6.

12. Greaves N, Nicholson J. Single incision laparoscopic surgery in general surgery: a review. Ann R Coll Surg Eng 2011;93(6):437-440. DOI: 10.1308/003588411X590358.

13. Hirano D, Minei $S$, et al. Retroperitoneoscopic adrenalectomy for adrenal tumors via a single large port. J Endourol 2005;19(7):788-792. DOI: 10.1089/end.2005.19.788.

14. Vidal $\mathrm{O}$, Valentini $\mathrm{M}$, et al. Laparoendoscopic single-site surgery appendectomy. Surg Endosc 2010;24(3):686-691. DOI: 10.1007/ s00464-009-0661-6. 